\title{
THE SEVERITY OF WORK-RELATED STRESS AND AN ASSESSMENT OF THE AREAS OF WORKLIFE IN THE SERVICE SECTOR
}

\section{AGATA CHUDZICKA-CZUPAŁA ${ }^{1}$, MARTA STASIŁA-SIERADZKA² ${ }^{2}$ ŻANETA RACHWANIEC-SZCZECIŃSKA², and DAMIAN GRABOWSKI ${ }^{1}$}

\author{
${ }^{1}$ SWPS University of Social Sciences and Humanities, Katowice, Poland \\ Faculty of Psychology in Katowice, Department of Social and Organizational Behavior Psychology \\ ${ }^{2}$ University of Silesia, Katowice, Poland \\ Faculty of Pedagogy and Psychology, Institute of Psychology, Work and Organizational Psychology Department \\ ${ }^{3}$ Medical University of Silesia, Katowice, Poland \\ School of Health Sciences, Chair of Social Sciences and Humanities, Department of Psychology
}

\begin{abstract}
Objectives: The aim of the study was to examine the potential differences in the assessment of the severity of work-related stress, and in the global assessment of the areas of worklife and individual worklife dimensions in employees working in service occupations. Material and Methods: The research covered 61 emergency workers, 92 helping professionals, and 58 knowledge workers. A subjective assessment of the areas of worklife was carried out using the Areas of Worklife Survey, and the Perceived Stress Scale (PSS-10) was used to investigate stress severity. Results: The research has revealed statistically significant differences between workers belonging to the 3 groups of service occupations in their assessment of the severity of work-related stress. The findings have shown that $26 \%$ of the variance of the Stress Severity Assessment variable is explained by belonging to a specific occupational group. Police officers and helping professionals experience comparably severe stress, which is significantly stronger than that experienced by the laboratory staff. Statistically significant differences have also been found between the studied groups in terms of the global assessment of all areas of worklife, as well as in the assessment of particular areas, i.e., control, rewards, fairness and values. No significant differences have been found with regard to the workload and community areas. Conclusions: Working in social service occupations, whether as emergency or helping professionals, may lead to a similar level of stress severity. The surveyed workers do not differ in their assessment of workload or of the sense of trust, cooperation and support received from their co-workers. Further research should be carried out to explore the sources of stress, which may be linked to other factors than the areas of worklife presented here, such as stress inducing contact with customers, environmental determinants of work, existing hazards to life or health, or the intrinsic predispositions of individuals performing specific types of work and gender. Int J Occup Med Environ Health. 2019;32(4):569-84
\end{abstract}

Key words:

job stress, social professions, service professions, worklife areas, emergency professions, knowledge-based professions

\footnotetext{
Funding: this work was supported by the SWPS University of Social Sciences and Humanities, Warsaw, Poland (project No. 1571-BST/WZK/2018/A/06 entitled "Development of standards for the assessment of social and ethical aspects of employees' functioning," project manager: Agata Chudzicka-Czupała, Ph.D.). Received: December 4, 2018. Accepted: May 7, 2019.

Corresponding author: Agata Chudzicka-Czupała, SWPS University of Social Sciences and Humanities, Faculty of Psychology in Katowice, Department of Social and Organizational Behavior Psychology, Techników 9, 40-326 Katowice, Poland (e-mail: achudzicka-czupala@swps.edu.pl).
} 


\section{INTRODUCTION}

Work is a natural and desirable form of activity for human beings. Depending on the circumstances and on the goals set, it can be good for one's health, support one's development and provide satisfaction, but it can also be a pathogenic factor, or become a source of social and family disorders, emotional tension or illness. It has been known for many years that work-related stress is a very serious problem, both for the individuals experiencing it and for the organizations that incur significant financial losses as a result.

In 2017, psychosocial risks and stress experienced at work became so costly that they were identified as the most significant aspects related to occupational health and safety, requiring an intervention at the organizational level in the EU Member States. The data obtained show that currently $>50 \%$ of all workers in the Member States consider stress in the workplace as a common phenomenon, and 4 out of 10 respondents say that they are unable to cope with it. Stress contributes to about $50 \%$ of all lost working days, due to the relatively long period of absence from work, and it leads to a significant reduction in productivity and a 5-fold increase in the number of accidents. Stress also causes about $20 \%$ of all staff changes in enterprises [1].

The changes currently observed in the working environment make the aspects related to its stress-inducing nature go far beyond the aspects related to a single occupation. Therefore, contemporary researchers investigating these matters have been focusing more on studying the entire groups of occupations and comparing their representatives. On the one hand, a significant number of studies can be observed concerning professional groups traditionally perceived in the area of services as particularly demanding, e.g., the police, rescue services, uniformed services, professional soldiers, teachers, and community workers [2-4]. On the other hand, one can see the emerging tendency to compare the stress-inducing nature of work in different industries or occupations belonging to all $3 \mathrm{sec}-$ tors of the economy [5-7]. While it is difficult to clearly determine which research approach, the one focusing on a single occupation or the one that is industry-specific, is more justified in terms of prevention needs, it is important to bear in mind that the choice of the industry or individual occupation taken into account in the research conducted to date has been exclusively dictated by the objectives pursued by specific researchers. Moreover, its nature has been rather arbitrary, or even random, and the results obtained have often been mutually exclusive.

In addition, cultural transformations and technological progress have caused the working environment to change more dynamically. The emergence of new occupations and new burdens accompanying them, as well as the changing labor market, make the subject of work-related stress an area where research exploration is needed, which should take into account the internal diversification of the economy sectors identified until now. Although stress and its sources are among the most frequently studied variables, the assessment of individual areas of social life which might lead to stress, in particular using the approach presented later in the paper, has not been the subject of comparative analyses. The aim of the research discussed herein is to fill, at least partly, the existing gap. The selection of the group for the study, i.e., representatives of service occupations, is related to the fact that services constitute the most dynamically developing sector of the economy, where the largest group of the working population has found employment. As work in service occupations is becoming increasingly demanding, it generates stress, making the services sector one of the most significant research areas, due to the particular risks to workers' health present there.

\section{Sources of stress and its severity in service professions}

One of the reasons for the growing sense of stress among the working population is the increase in employment in the services sector, where numerous sources of work-related psychological burdens are observed [8]. The results of 
a study concerning occupational stress, conducted in 2017 by Career, an American job portal, among workers representing 200 professions and all sectors of the economy, indicate that the 10 most stressful occupations are service professions [9]. The gradually growing employment in this sector, characterizing the majority of developed economies, has also been changing the Polish labor market reality. In 2000, the share of services in total employment exceeded 50\%, and in Q2 2017, as many as 57.8\% of working Poles were employed in services [10].

In today's economies, services play a key role, being the major source of increase in the number of available jobs. They determine the efficient performance of manufacturing processes, and some of them also cater to people's social needs. However, as the economy is moving away from the rigid division into 3 sectors, the changes taking place within them are becoming increasingly important, triggering the need for research conducted at a lower level of aggregation. Currently, service activity is increasingly often analyzed from the perspective of the 2 categories of professions that make it up. The first one includes social services occupations that involve helping others, which require acting for the benefit of other individuals, as well as direct contact with the client. This group includes professions such as therapist, teacher, social worker, and police officer. The second category consists of "knowledge-intensive" occupations, based on specialist knowledge, related to modern technologies and requiring creativity. Research institute workers, technological laboratory workers, and information technology specialists in IT companies are among those professionals [11].

Helping professions involve intensive contact with people, which often becomes a source of severe stress. Apart from this factor, which leads to work overload, both in qualitative and quantitative terms, stress in these occupations may result from increased bureaucratization, from having to comply with legal provisions and other rigid regulations at work, from the inability to maintain a work-life balance, and from the lack of support from employers who have high expectations and offer low remuneration $[2,3,12]$. Jenaro et al. [13] list the lack of satisfaction with work as one of the significant factors increasing the level of stress in helping professionals. The latter name increasingly often the growing demands of clients and the quality of the relations established with them as important sources of frustration related to dissatisfaction with work. The client is perceived as a narcissistic individual with a demanding attitude [4]. Research [14-16] shows that the demanding attitude on the part of clients makes it difficult for helping professionals to establish a relationship based on empathy and understanding, leading to more severe stress and burnout.

Similarly, research conducted among clinical psychologists [17] confirms that the specificity of the client, whose behavior is widely recognized as the most important stress factor, can be a significant problem. The dissatisfaction expressed by those receiving help results in the inability to feel the rewarding aspect of one's work, and makes one belittle its value. This, when combined with the declining social prestige of the professions in question, may constitute an additional source of stress for the individuals pursuing them.

The demanding attitude and excessive expectations of the clients are not the only causes of stress in helping professions. Other factors that significantly increase the level of frustration include the feeling of helplessness, which may be caused by the fact that the actions undertaken very rarely bring about a significant improvement in the situation or condition of the assisted persons. This is due to the chronic illnesses or disabilities the clients have to struggle with, or to their difficult financial and social situation, which the social services workers are unable to change or improve due to the lack of sufficient resources or ability to meet the needs of those under their care [3]. When looking at helping professions, one should also take into account the specificities of the stressors that may be con- 
nected with the environmental factors related to the work performed. Some of them are connected with the need to participate in some traumatic situations. Emergency and rescue workers are frequently exposed to particularly strong stress factors, often exceeding their ability to adapt and their immune resources. This kind of work is characterized by having to participate in difficult situations, involving life and health risks, as well as high exposure to trauma when performing the relevant tasks.

The literature concerning stress factors typical of helping professions is extensive. A review of the findings indicates that the most significant sources of stress in the professional group of police officers may be considered to include the perceived threat to life and the risk of injury, factors directly related to the specificity of the job and the manner of its performance, as well as to the culture within the organization, relations with co-workers, the excessive requirements imposed on police officers or the conflict of roles - the impossibility of meeting the contradictory expectations on the part of different individuals, such as co-workers, superiors, i.e., public prosecutors and probation officers, as well as family members, which is connected with the simultaneous functioning within the organization and outside it. They also include factors which are related, to a smaller extent, to the job itself, for instance, expectations on the part of the general public with regard to representatives of this professional group, as well as health and diet [18].

The results of research comparing the severity of stress experienced by representatives of emergency occupations, for instance, police officers, and by other helping professionals, are not unambiguous. The results of a comparison of 26 occupational groups in terms of the severity of workrelated stress indicate that teachers and social workers community workers, customer service workers and police officers are among those threatened with the most severe stress [19].

Sigler et al. [20] revealed that the level of work-related stress among police officers and teachers in some localities did not differ; in some cases police officers experienced more severe stress than teachers, while in others teachers were more stressed than police officers. Ogińska-Bulik [21] argues that "the professional burnout rates among police officers are close to the rates in the occupational groups traditionally associated with that phenomenon, namely social services occupations such as teachers, doctors, nurses, and community workers, in which close interpersonal contacts, as well as processes of involvement and emotional exchange, play a significant role." The author points out that police officers demonstrate a slightly lower level of emotional exhaustion than the group of doctors and nurses studied, and a significantly lower level compared to teachers. Given that work in emergency occupations is commonly regarded as the most stressful, which is also confirmed by some researchers [22], and in view of the results of the studies quoted above, which have shown that stress in other helping professions may be higher, the authors of this paper have decided to compare these occupational groups in terms of the severity of work-related stress.

Servicization of the economy, i.e., the penetration of services into all its fields, has been drawing researchers' attention to occupations which inherently involve using advanced knowledge. Such occupations offer significant potential in terms of employment growth in the coming years, as the importance of technologically advanced sectors is growing. "Knowledge-intensive" services are based on professional, specialist knowledge, which is reflected, for instance, in the structure of employment in the relevant area, dominated by people with higher education and highly qualified specialists. Such service activities, combined with scientific and creative work, are a source of specific "products" providing information and knowledge to other users, for example, in the form of analyses, reports, new solutions, materials, or devices. The specific nature of knowledge-intensive services points to the importance of customer relations, built in the process of con- 
tinuous learning, communication and developing the ability to cooperate within interdisciplinary teams. Taking into account the fact that the final form of the services often constitutes the solution to a specific problem, developed together with the client, their quality is largely determined by correct interactions between both parties to the respective transaction. Combining these factors with abstract thinking and creative problem solving contributes to the successful performance of such services [11].

The increased severity of work-related stress may result in this case from excessive expectations of the employees themselves with regard to the work they take up, from the wish to meet the client's requirements, from the sense of expert and financial responsibility for the projects created and conducted, and for the expert opinions prepared, or from the inability to satisfy their own inflated ambitions. The ability to communicate effectively with other team members and experiencing pressure resulting from the lack of time, or from the nature of the requirements imposed on employees, are also significant. Stress may be further exacerbated by macroeconomic changes, translating into the availability of funds for project implementation, such as recession [23].

The sources of stress in laboratory work are also often considered to include disruptions in interpersonal communication between workers [24]. Canadian researchers also point out that specialists working in laboratories are often exposed to a high degree of unethical behavior on the part of their superiors and co-workers, indicated by $91 \%$ of those surveyed, which tends to be related to the excessive amount of responsibilities imposed on them due to staff shortage and work overload, and that their stress also results from inadequate training $(57 \%)$ and inappropriate working relationships (56\%). Over $30 \%$ of the respondents obtained results pointing to a high level of stress which they regularly experienced in the workplace. However, the majority of the respondents (52\%) experienced a moderate level of stress [25].
The absence of detailed comparisons of the severity of stress between representatives of knowledge-based occupations and helping professionals/emergency workers encouraged the authors of this paper to include that group of individuals in the sample.

\section{Psychosocial hazards in the working environment - the importance of the assessment of worklife areas} The International Labour Organization defines psychosocial hazards as interactions between the job content, the work process organization and management, as well as other environmental determinants, on the one hand, and the workers' capacities and needs, on the other. The hazards refer to the interactions for which it has been demonstrated that experiencing them, and even the very feeling of being threatened by them, entails a risk to workers' health. Psychosocial hazards can also be defined as aspects of the working process design and management that may potentially cause psychological or physical harm, and have a negative impact on the overall social and organizational context [7].

With regard to the assessment of the working environment, particularly interesting, in diagnostic terms, is the proposal put forward by Leiter and Maslach [26,27]. It takes into account 5 main spheres of people's occupational activity, i.e., the areas of worklife, constituting resources whose loss is a source of stress. The aforementioned researchers refer to the person-environment fit model, based on the assumption that a better fit between the individual and the job contributes to adaptation and determines the severity of subjectively perceived stress. According to that concept, if the work requirements and the conditions which the organization creates do not meet workers' expectations or needs, deficiencies appear in the areas listed below, resulting in dissatisfaction and negative assessment which potentially lead to work-related stress. The areas of worklife defined by the researchers refer to the professions pursued by representatives of all 
sectors of the economy. They are universal in their nature and constitute an attempt to look at the conditions of its performance in a holistic manner.

There are 5 areas in which a mismatch is possible between work and people's expectations. In these spheres, according to Leiter [26], the mismatch occurs most often. They are listed and described below:

1. Workload - occurring when the worker is unable to meet all the requirements within the specified time, and up to the specified standard, in terms of the quality of performance - excessive workload is one of the main sources of stress.

2. Autonomy or sense of control - allowing the worker to decide on the manner and scope of task performance in particular excessive control and limiting the worker's influence on the manner in which the tasks are performed constitute sources of stress at work.

3. Perceived organizational support - the workers' conviction that the employer cares about their well-being. The perceived support concerns the social and emotional sphere, as well as securing access to work tools and technologies. This area also refers to the sense of being paid fairly for one's work, and the sense of being recognized for one's commitment - if the support is perceived as low, it leads to reduced self-esteem and professional competencies, and may ultimately cause stress.

4. Work support - referring to social relations in the workplace and including instrumental and emotional manifestations of support on the part of co-workers or supervisors, thus helping the worker to cope with stress and alleviating its effects.

5. Congruence of the worker and organization's values describing the convergence between the worker's values and the respective organization's culture. It also concerns the worker's attitude to the goals set by the organization - the more the employees identify with the organization's values, the less they experience stress [13].

\section{Research problem and questions}

The main aim of the research was to answer a set of questions concerning the differences in assessing the severity of work-related stress and the areas of worklife between representatives of 3 groups of service occupations, classified as:

- emergency workers - the research covered police officers;

- helping professionals - these included psychologists, therapists, community workers, special education teachers;

- knowledge-based occupations - the studied group included staff of a chemical research laboratory.

The research questions set forth below were formulated on the basis of the above literature review and reports on research performed by other authors, resulting in contradictory information concerning potential differences in assessing the severity of stress between the groups covered by the research:

- Question 1. Do significant differences exist between workers belonging to the 3 groups of service occupations in their assessment of the severity of work-related stress? With regard to the areas of professional life studied, there are no grounds to put forward any hypotheses, as the perception of such areas, from the perspective adopted by Leiter and Maslach [26], has not constituted the subject of research or comparisons between representatives of the selected occupational groups earlier. The nature of this part of the study is, therefore, also exploratory. The research questions put forward take into account both the differences in the severity of the variable, considered globally, and the differences with regard to its individual components:

- Question 2. Do significant differences exist between workers belonging to the 3 groups of service occupations in their global assessment of all the dimensions of the working environment (all areas of worklife)? 
- Question 3. Do significant differences exist between workers belonging to the 3 groups of service occupations in their assessment of individual dimensions of the working environment (specific areas of worklife), i.e., workload, control, rewards, community, fairness and values?

\section{MATERIAL AND METHODS}

\section{Study sample}

The research was conducted in 2017-2018 in the Silesia region. Selection to the groups was targeted and based on the criteria related to fact that the respondents belonged to 1 of the 3 selected groups of service occupations, classified as emergency occupations, helping professions, and knowledge-based occupations. In the group of emergency occupations, 61 police officers were surveyed, the helping professionals group included 92 psychologists, therapists, community workers and special educators, and the group of knowledge-based occupations included 58 workers employed at a specialist chemical laboratory, a research institution. Table 1 shows the study subjects' profiles. It presents socio-demographic data of the respondents belonging to the individual service occupation groups (including age, gender and job seniority).

Each survey was preceded by direct contact between the researcher and the respondents, during which the purpose of the research was presented and the research tools to be used were discussed. Questionnaires were filled in the paper-pencil form. The research was anonymous and conducted with the consent of the persons managing the individual institutions, in the premises of these institutions, on a group basis. Employees absent at the time when the study was being carried out were allowed to fill out the questionnaire via Internet. Participation in the survey was voluntary and anonymous, and ethical standards were observed when it was conducted. The respondents were told that that were allowed to withdraw from the survey at any time.

\section{Methods}

The respondents assessed the severity of work-related stress using the Perceived Stress Scale (PSS-10) by Cohen et al. [28], in the Polish adaptation by Juczyński and Ogińska-Bulik - Skala Odczuwanego Stresu [29]. The scale contains 10 statements. The respondents' task was to take a position on them using a Likert scale, with 0 meaning "never" and 4 meaning "very often." The survey using the said scale was preceded by an additional instruction to refer every statement to one's thoughts and feelings related to events experienced at work over the previous month. The areas of worklife were assessed using the Areas of Worklife Survey questionnaire by Maslach and Leiter

Table 1. A socio-demographic profile of the samples: emergency workers, helping professionals and knowledge workers in the study on the severity of work-related stress, conducted in 2017-2018 in the Silesia region

\begin{tabular}{lccc}
\hline \multicolumn{1}{c}{ Variable } & $\begin{array}{c}\text { Sample A } \\
(\mathrm{N}=61)\end{array}$ & $\begin{array}{c}\text { Sample B } \\
(\mathrm{N}=92)\end{array}$ & $\begin{array}{c}\text { Sample C } \\
(\mathrm{N}=58)\end{array}$ \\
\hline $\begin{array}{l}\text { Gender [n }(\%)] \\
\text { female }\end{array}$ & $11(18)$ & $68(74)$ & $18(60)$ \\
$\quad$ male & $50(82)$ & $24(26)$ & $12(40)$ \\
Age $(\mathrm{M} \pm \mathrm{SD})$ & $38.9 \pm 6.29$ & $34.37 \pm 8.99$ & $39.38 \pm 11.94$ \\
Job seniority [years] $(\mathrm{M} \pm \mathrm{SD})$ & $14.26 \pm 7.18$ & $7.54 \pm 7.20$ & $13.66 \pm 11.40$ \\
\hline
\end{tabular}

Sample A - emergency workers (policemen).

Sample B - helping professionals (psychologists, therapists, community workers, special education teachers).

Sample C - knowledge workers (chemical laboratory workers). 
$[26,27]$ in the Polish adaptation by Terelak and Izwantowska (Kwestionariusz Obszary Życia Zawodowego) [30]. This method is used to assess the functioning of an employee in the working environment in the individual areas, and to identify inconsistencies between the organization's requirements and the respondents' aspirations, capacities, and needs. The questionnaire consists of 29 statements, grouped together and forming 6 scales:

- the Workload scale, concerning the feeling of being burdened with work, i.e., whether the respondents consider the workplace situation and the duties entrusted to them as ones they can cope with, or whether they feel overwhelmed and overburdened with excessive workload;

- the Control scale, assessing the possibility of making decisions and choices independently from other persons;

- the Reward scale, assessing the degree of satisfaction with the rewards the workers obtain for their work, including tangible rewards, prospects of promotion, as well as social rewards, such as recognition and respect from co-workers, superiors, and clients;

- the Community scale, assessing the quality of the social environment in the workplace, i.e., the sense of mutual support, cooperation and positive feelings the team members show to each other;
- the Fairness scale, related to the workers' sense of being treated fairly and concerning such aspects of work as clear rules, distribution of resources, and prospects of promotion;

- the Values scale, making it possible to assess whether there is a conflict of values within the organization itself, or between the workers' values and the values followed and promoted by the organization.

The respondents' task was to take a position on each statement included in the questionnaire, using a Likert scale, with 1 meaning "I definitely disagree," and 5 meaning "I strongly agree." The factorial validity determined using the principal component factor analysis with Kaiser's Varimax rotation confirmed the factorial validity of the questionnaire [31].

Table 2 shows the Cronbach's $\alpha$ reliability coefficients for the scales in relation to the research tools used for each study sample.

\section{Statistical methods}

A 1-factor MANOVA analysis was performed to answer the research questions put forward. Univariate F-tests were used to answer questions 1 and 3, and to answer question 2 a multivariate test was used. The adoption of

Table 2. Reliability estimates for the scales of the areas of worklife and stress severity assessment in each sample: emergency workers, helping professionals and knowledge workers in the study conducted in 2017-2018 in the Silesia region

\begin{tabular}{lccc}
\hline & \multicolumn{3}{c}{ Cronbach's $\alpha$} \\
\cline { 2 - 4 } & Scale & sample A & sample B \\
$(\mathrm{N}=61)$ & $(\mathrm{N}=92)$ & $\begin{array}{c}\text { sample C } \\
(\mathrm{N}=58)\end{array}$ \\
\hline Workload & 0.72 & 0.76 & 0.85 \\
Control & 0.68 & 0.69 & 0.79 \\
Reward & 0.68 & 0.87 & 0.77 \\
Community & 0.84 & 0.87 & 0.89 \\
Fairness & 0.80 & 0.82 & 0.85 \\
Values & 0.71 & 0.77 & 0.72 \\
Perceived Stress & 0.68 & 0.89 & 0.71 \\
\hline
\end{tabular}

Explanations as in Table 1. 
such an analysis model is "an optimal choice when the researcher treats the explained measurable variables as interrelated and thus as ones creating a relational structure of properties which can be meaningfully and substantively interpreted, in whole or in part" [31], and this is the case with respect to the assessment of the individual areas of worklife. Additionally, Student's t-test was performed in order to capture the differences existing between particular groups of subjects with regard to each dependent variable. The statistical analyses were carried out using the STATISTICA 12 statistical package.

\section{RESULTS}

Descriptive statistics concerning all the studied variables (the mean values obtained and the standard deviations) for each group of the study subjects, representing the 3 groups of service occupations, are presented in Table 3.

Table 4 contains the intercorrelations between the studied variables for all the 3 groups that were studied.

Since the study bears the hallmarks of exploratory research, univariate F-tests were used to answer questions 1 and 3, making it possible to determine the significance of differences between the results of individuals in the 3 groups that were studied, in terms of the severity of work-related stress, measured using the PSS-10 [29] and the assessment of each area of worklife separately (the assessments were measured using the Areas of Worklife Survey [30]). The results of the MANOVA 1-factor analysis are presented in Table 5.

The findings prove the existence of statistically significant differences between workers belonging to the 3 groups of service occupations in their assessment of the severity of work-related stress. The univariate F-test value is statistically significant (Table 5). On the basis of the results, an affirmative answer may be given to question 1 .

In order to answer question 2, concerning the existence of a statistically significant difference between the studied representatives of the 3 selected groups of service occupations in terms of the global assessment of all areas of worklife (working environment dimensions), a multivariate test was used, and an analysis was performed of the significance of differences between the average results of the Areas of Worklife Survey [30] obtained by the respondents belonging to all the 3 groups of service occupations. The results presented in Table 5 prove the existence of a statistically significant difference between the studied representatives of the 3 selected groups of service occupations, in terms of the global assessment of all areas of

Table 3. Descriptive statistics of the examined variables: the areas of worklife and stress severity assessment in the study conducted in 2017-2018 in the Silesia region

\begin{tabular}{lcccccc}
\hline & \multicolumn{2}{c}{$\begin{array}{c}\text { Sample A } \\
(\mathrm{N}=61)\end{array}$} & \multicolumn{2}{c}{$\begin{array}{c}\text { Sample B } \\
(\mathrm{N}=92)\end{array}$} & \multicolumn{2}{c}{$\begin{array}{c}\text { Sample C } \\
(\mathrm{N}=58)\end{array}$} \\
\cline { 2 - 7 } & $\mathrm{M}$ & $\mathrm{SD}$ & $\mathrm{M}$ & $\mathrm{SD}$ & $\mathrm{M}$ & $\mathrm{SD}$ \\
\hline Workload & 2.94 & 0.79 & 2.94 & 0.85 & 2.80 & 0.58 \\
Control & 3.36 & 0.80 & 3.70 & 0.88 & 3.71 & 0.83 \\
Reward & 3.06 & 0.66 & 3.47 & 0.99 & 3.55 & 0.65 \\
Community & 3.44 & 0.71 & 3.59 & 0.90 & 3.70 & 0.87 \\
Fairness & 2.45 & 0.75 & 2.82 & 0.89 & 2.58 & 0.70 \\
Values & 3.08 & 0.68 & 3.46 & 0.80 & 3.28 & 0.55 \\
Perceived Stress & 27.25 & 4.67 & 26.35 & 8.33 & 15.45 & 6.20 \\
\hline
\end{tabular}

Explanations as in Table 1. 
Table 4. Correlations between the examined variables (the areas of worklife and stress severity assessment) in each sample in the study conducted in 2017-2018 in the Silesia region

\begin{tabular}{|c|c|c|c|c|c|c|}
\hline \multirow{2}{*}{ Variable } & \multicolumn{6}{|c|}{ Correlations } \\
\hline & 1 & 2 & 3 & 4 & 5 & 6 \\
\hline \multicolumn{7}{|l|}{ Sample A $(\mathrm{N}=61)$} \\
\hline \multicolumn{7}{|l|}{ Workload } \\
\hline Control & $0.27^{*}$ & & & & & \\
\hline Reward & 0.25 & $0.33^{* *}$ & & & & \\
\hline Community & 0.07 & 0.15 & $0.36 * *$ & & & \\
\hline Fairness & 0.02 & $0.42 * *$ & $0.44 * *$ & 0.25 & & \\
\hline Values & -0.06 & $0.27^{*}$ & 0.25 & $0.39 * *$ & $0.41^{* *}$ & \\
\hline Perceived Stress & $-0.54^{* *}$ & $-0.32 *$ & $-0.37^{* *}$ & $-0.28^{*}$ & -0.07 & -0.21 \\
\hline \multicolumn{7}{|l|}{ Sample B $(\mathrm{N}=92)$} \\
\hline \multicolumn{7}{|l|}{ Workload } \\
\hline Control & $0.39 * *$ & & & & & \\
\hline Reward & $0.32 * *$ & $0.51^{* *}$ & & & & \\
\hline Community & $0.30 * *$ & $0.40^{* *}$ & $0.42 * *$ & & & \\
\hline Fairness & $0.41^{* *}$ & $0.55^{* *}$ & $0.64 * *$ & $0.52^{* *}$ & & \\
\hline Values & $0.27 * *$ & $0.67^{* *}$ & $0.54 * *$ & $0.44^{* *}$ & $0.59 * *$ & \\
\hline Perceived Stress & $-0.61^{* *}$ & $-0.47^{* *}$ & $-0.52 * *$ & $-0.37^{* *}$ & $-0.42 * *$ & $-0.32 * *$ \\
\hline \multicolumn{7}{|l|}{ Sample C $(\mathrm{N}=58)$} \\
\hline \multicolumn{7}{|l|}{ Workload } \\
\hline Control & $0.42 *$ & & & & & \\
\hline Reward & -0.08 & 0.29 & & & & \\
\hline Community & 0.11 & 0.32 & $0.65^{* *}$ & & & \\
\hline Fairness & 0.36 & $0.64 * *$ & 0.24 & $0.42 *$ & & \\
\hline Values & 0.26 & $0.54^{* *}$ & $0.42^{*}$ & $0.55^{* *}$ & $0.61^{* *}$ & \\
\hline Perceived Stress & $-0.67^{* *}$ & $-0.48^{* *}$ & -0.19 & -0.05 & -0.27 & -0.31 \\
\hline
\end{tabular}

Explanations as in Table 1.

${ }^{* *} \mathrm{p}<0.01 ;{ }^{*} \mathrm{p}<0.05$.

Table 5. MANOVA variance analysis ${ }^{\mathrm{a}}$ for the examined variables: the areas of worklife and stress severity assessment in the study conducted in 2017-2018 in the Silesia region

\begin{tabular}{lccccc}
\hline & Variable & One-effect & Adjusted & \multicolumn{3}{c}{ Student's t-test } \\
\cline { 5 - 6 } & test $\mathrm{F}$ & $\mathrm{R}^{2}$ & $\mathrm{~A}-\mathrm{B}$ & $\mathrm{A}-\mathrm{C}$ & $\mathrm{B}-\mathrm{C}$ \\
\hline Workload & 0.39 & 0.01 & -0.04 & 0.84 & 0.84 \\
Control & $3.38^{*}$ & 0.03 & $-2.43^{*}$ & -1.95 & -0.09 \\
Reward & $5.37^{* *}$ & 0.05 & $-2.84^{* *}$ & $-3.34^{* *}$ & -0.43 \\
\hline
\end{tabular}


Table 5. MANOVA variance analysis ${ }^{\mathrm{a}}$ for the examined variables: the areas of worklife and stress severity assessment in the study conducted in 2017-2018 in the Silesia region - cont.

\begin{tabular}{lccccc}
\hline \multirow{2}{*}{ Variable } & \multirow{2}{*}{$\begin{array}{c}\text { One-effect } \\
\text { test } \mathrm{F}\end{array}$} & Adjusted & \multicolumn{3}{c}{ Student's t-test } \\
\cline { 5 - 6 } & 1.08 & $\mathrm{R}^{2}$ & $\mathrm{~A}-\mathrm{B}$ & $\mathrm{A}-\mathrm{C}$ & $\mathrm{B}-\mathrm{C}$ \\
\hline Community & $3.86^{*}$ & 0.03 & -1.06 & -1.51 & -0.61 \\
Fairness & $5.03^{* *}$ & 0.04 & $-2.66^{* *}$ & -0.81 & 1.29 \\
Values & $32.03^{* *}$ & 0.26 & $-3.05^{* *}$ & -1.43 & 1.09 \\
Perceived Stress & & 0.76 & $10.00^{* *}$ & $6.50^{* *}$ \\
\hline
\end{tabular}

aAll effects Wilks' test for the "Areas of Worklife" construct : $F=1.97, p=0.02$, partial $\eta^{2}=0.06$.

Student's t-test values - the significance of differences between the mean values for samples A, B and C.

${ }^{*} \mathrm{p}=0.05 ; * * \mathrm{p}=0.01$.

worklife. The value of Wilks' multivariate F-test, which is statistically significant, proves that the studied groups differ significantly. On the basis of the results, an affirmative answer can be given to question 2 .

A univariate F-test for the individual areas of worklife was used to answer question 3. The results show that the studied groups of service employees differ significantly in the areas of Control, Rewards, Fairness, and Values. For the areas mentioned above, the values of the univariate F-test are statistically significant. On this basis, an affirmative answer can be given to research questions $3 \mathrm{~b}, 3 \mathrm{c}, 3 \mathrm{e}$, and $3 \mathrm{f}$. No significant differences were found between the results of workers belonging to the 3 analyzed groups of service professions in terms of the assessment of the remaining areas of worklife, i.e., Workload and Community, so a negative answer should be given to questions $3 \mathrm{a}$ and $3 \mathrm{~d}$.

\section{DISCUSSION}

The results prove that significant differences exist between workers belonging to the 3 groups of service professions that were studied. The differences that were identified concern in particular the severity of the work-related stress they experience. The effect size (Table 5) is relatively high here, as $26 \%$ of the variance of the Stress Severity Assessment variable is explained by the determining factor, i.e., belonging to a specific occupational group. As shown by the Student's t-test values for the independent groups (Table 5), laboratory workers, representatives of knowledgebased professions, differ significantly from both police officers and helping professionals in terms of the severity of stress they experience. Police officers and helping professionals experience significantly stronger stress at work compared to the laboratory staff (Table 3).

However, there are no significant differences in terms of the severity of stress between police officers and helping professionals. It turns out that the assessment of stress severity by emergency workers, i.e., the police officers who were surveyed, is not significantly higher than the assessment of the severity of stress experienced by helping professionals, i.e., the psychologists, therapists, community workers, and special educators who were surveyed.

This result may also come from the clear gender disproportion between the respondents - men prevailed significantly $(82 \%)$ in the group of police officers, while women prevailed in the helping professionals group (74\%). Although this particular composition of the sample results from the specific nature of the relevant occupations - males generally prevail among police officers, while the occupations of psychologist, community worker and educator are feminized - this disproportion may be significant.

The result obtained confirms the results of research in the same area quoted above and the statements made by 
other authors, who demonstrated that female police officers were generally more stressed than men performing the same profession, due to the lack of support, both on the part of male co-workers and the organization [32]. Other authors, in extensive research conducted in various regions in the world, demonstrated that although there were no differences between the levels of stress experienced by men and women (except stress resulting from the organizational climate), there were significant differences between the 2 sexes in terms of the manner of experiencing stress - the psychological and physical wellbeing of men was significantly higher, and they felt better $[33,34]$. This confirms that representatives of both sexes, in similar positions within the organization and the same functions, generally experience stress for the same reason, but they are characterized by different levels of anxiety. This phenomenon may have also influenced the results of the comparison presented here. This is in line with the results of research in the field of psychology of individual differences, which shows that women are more neurotic and emotionally reactive, with their temperament, which predisposes them to a quicker reaction of that type, potentially making them less resistant to stress [35].

Moreover, it may also be significant that, in the case of the male respondents, both the traditional norm of masculinity and the imperatives related to the professional role of police officers do not allow them to admit to mental weakness, which may have encouraged them to show themselves as individuals experiencing less severe work-related stress, even if they did feel weakness or helplessness. Police officers may also feel the pressure related to the wish to continue their career, to create an image of themselves as mentally strong individuals, which may lead to insincere answers in surveys concerning the sources and intensity of stress, and to hiding the problems experienced [36]. In subsequent studies, one should, therefore, make sure that there are equal proportions of men and women in the sample. The significance of selected personality and psychological traits, as well as that of gender, should be checked, and the role of social support received from both male and female co-workers should be monitored.

The absence of differences between representatives of emergency professions and helping professionals may also result from the fact that the work of helping professionals, contrary to that of police officers, also involves contact with clients whose behavior is a source of stress. Representatives of such occupations experience numerous limitations attributable to the respective organizations, which make it impossible to perform the tasks to an appropriate quality standard $[15,37]$.

At the same time, the chemical laboratory workers, representing a knowledge-based occupation, experienced significantly lower stress. Stressors which pose a threat to life and health, such as the threat of violence and working with aggressive or demanding clients, are apparently more stressful than factors impacting on the psychological well-being of chemical laboratory workers. These findings require further empirical explorations, also among representatives of other emergency, helping and knowledgebased professions.

The results also prove the existence of a statistically significant difference between the studied representatives of the selected groups of service occupations, in terms of the global assessment of all areas of worklife. The effect magnitude (Table 5) is relatively low in this case, as only $6 \%$ of the variance of the Areas of Worklife Assessment variable is explained by belonging to specified occupational groups. The studied groups of service professionals differ most strongly in terms of the Rewards and Values, as well as Fairness and Control areas. No significant differences are found between representatives of the studied service occupation groups in the Workload and Community areas. The effect size (adjusted $\mathrm{R}^{2}$ - Table 5) for the individual components of the Areas of Worklife Assessment construct is also low. This means that the size of the explained variance for the assessment of particular areas of worklife 
ranges $0-5 \%$. Belonging to particular groups explains the respondents' different assessment of the selected areas to a small, but statistically significant, degree.

Analyses of the Student's t-test values point to the existence of differences in the assessment of the Rewards area between police officers and the other 2 groups, meaning that police officers give this area the lowest rating, and a significantly lower rating when compared to helping professionals and the laboratory staff. Police officers turn out to be the least satisfied with this area of their work. They are also significantly less satisfied with the Values, Fairness and Control areas compared to helping professionals. Apart from the Values area already mentioned above, there are no statistically significant differences between police officers and laboratory workers with regard to the areas that were assessed. The other 2 groups of service workers, i.e., helping professionals and the laboratory staff, did not differ significantly in the assessment of any areas of worklife.

The results show that police officers are significantly less satisfied than helping professionals (psychologists, therapists, community workers, and special educators), and less satisfied than laboratory workers, with the rewards they receive for their work, in terms of their sense of being appreciated, and in terms of prestige and recognition from co-workers, superiors or third parties. The feeling that their work is appreciated is significantly lower in their case.

Police officers also experience, to a significantly higher degree than helping professionals, conflicts of values within the organization itself or inconsistencies between their own values and those promoted by the organization employing them. Significant differences between the 2 groups of workers also relate to the sense of being treated fairly when it comes to promotion or distribution of resources (police officers have a significantly lower sense of justice than helping professionals). Their sense of autonomy, control and influence on the way they perform their work is also lower compared to helping professionals, and their access to appropriate working tools is also more restricted.

The service occupation groups that were studied do not differ significantly in terms of their assessment of the Workload area - the sense of time deficiency or being burdened with excessive responsibilities, and the fatigue resulting from work. There are no significant differences between them, when it comes to the assessment of the Community area, i.e., in terms of the sense of trust, cooperation and support received from co-workers.

\section{CONCLUSIONS}

The research has revealed significant differences between workers belonging to the 3 groups of service professions that were studied. The differences identified concern in particular the severity of the work-related stress they experience. Police officers and helping professionals experience significantly more severe stress at work compared to the laboratory staff. However, there are no significant differences in terms of the severity of stress between police officers and helping professionals. This result is probably related to the specific nature of work in the occupations in question.

Despite larger deficiencies in 4 areas of worklife (Rewards, Values, Fairness, and Control) in the group of police officers, compared to helping professionals, representatives of the respective occupational groups judged the severity of work-related stress similarly. This result shows that both emergency and helping professions may experience a comparably strong sense of stress. This is probably due to the fact that the sources of perceived stress may be linked to other specific factors, not taken into account in the study of the areas of worklife presented here, for instance, to aspects related to stress-inducing contact with clients, already mentioned in the introduction to this paper, environmental determinants of work, and the specific types of hazards to life and health [38-42]. It is also possible that 
the result is related to the fact that men prevailed in the group of police officers studied, while women prevailed in the group of helping professionals. Police officers and helping professionals experience more severe stress than the laboratory staff.

The studied groups of service occupations do not differ significantly in terms of their assessment of time deficiency, workload, and the resulting fatigue. There are no significant differences between them in terms of their assessment of the sense of trust, cooperation and support received from co-workers.

However, the research presented in this paper did not take into account individual factors related to personality traits or other inherent predispositions of individuals working in the relevant occupations. Excessive, unrealistic expectations as to the outcome of one's own work, the possibility of providing effective support or finding an optimal solution, combined with the efforts made in order to develop or find new ideas, may result in higher psychophysical exhaustion. This is likely to be influenced by selected personality traits, such as internal or external locus of control, self-esteem, performance motivation, or other individual features. Therefore, the authors of this paper believe that it would be desirable to supplement the area of research with other external determinants, related to the specificity of work in particular groups of service occupations, as well as with the psychological features mentioned above. Extending the research to include these aspects seems to be another desirable goal. In fact, combining these factors into a single coherent model would make it possible to provide a more complete picture of the significant determinants of work-related stress in service occupations.

\section{ACKNOWLEDGMENTS}

The authors would like to express their gratitude to all of the participants of the study and to all the persons managing the institutions where the research took place for their help in collecting data.

\section{REFERENCES}

1. Europen Agency for Safety and Health at Work [Internet]. Brusseles: Psychosocial risks and stress at work; 2017 [cited 2018 Mar 15]. Available from:https://osha.europa.eu/en/ themes/psychosocial-risks-and-stress.

2. Waszkowska M. [Stress in social workers]. In: Waszkowska M, Potocka A, Wojtaszczyk E, editors. [Workplace that lives up to expectations. A guide for social workers]. Łódź: Nofer Institute of Occupational Medicine; 2010. p. 57-70. Polish.

3. Chudzicka-Czupała A, Stasiła-Sieradzka M, Dobrowolska M, Kułakowska A. [Assessment of worklife areas and stress intensity among Border Guard officers]. Med Pr. 2018;69(2):199-210,https://doi.org/10.13075/mp.5893.00664. Polish.

4. Tucholska S. [Occupational burnout in teachers. Psychological analysis of the phenomenon and of its personality-related determinants]. Lublin: Wydawnictwo Katolickiego Uniwersytetu Lubelskiego; 2009. Polish.

5. Plopa M, Makarowski R. [Perceived Stress Questionnaire]. Warszawa: Wyższa Szkoła Finansów i Zarządzania; 2010. Polish

6. Orlak K, Gołuch D, Chmielewski J. [Stress at work and its influence on the occurrence of accidents at work and on workers' health]. Warszawa: Stowarzyszenie Dobra Praca; 2010. Polish.

7. Stavroula L, Aditya J. Health Impact of Psychosocial Hazards at Work: An Overview. Warszawa: Stowarzyszenie Zdrowa Praca; 2013.

8. Ogińska-Bulik N. [Work-related stress in social service occupations. Sources, consequences, prevention]. Warszawa: Difin; 2006. Polish.

9. CareerCast.com [Internet]. Most Stressful Jobs of 2017. Report; 2017 [cited 2018 Mar 9]. Available from: http://www.careercast.com/jobs-rated/most-stressful-jobs-2017? page $=0$.

10. Rynekpracy.org [Internet]. Workers employed in agriculture, industry and services; 2018 [cited 2018 Aug 21]. Available from: http://rynekpracy.org/x/989321. Polish. 
11. Skórska A. [Determinants and Perspectives of Service Sector Development in Poland - Intra-sector Changes]. Pol Geogr Soc. 2016;3(4):7-20. Polish.

12. Fengler J. [Helping is tiring]. Gdańsk: Gdańskie Wydawnictwo Psychologiczne; 2001. Polish.

13. Jenaro C, Flores N, Arias B. Burnout and coping in human service practitioners. Prof Psychol: Res Pract. 2007;38:80-7.

14. Hellman ID, Morrison TL. Practice setting and type of caseload as factors in psychotherapist stress. Psychother. 1987;24:427-33.

15. Kottler JA. Compassionate therapy: Working with difficult clients. San Francisco: Jossey-Bass; 1992.

16. Jenkis SR, Maslach C. Psychological health and involvement in interpersonally demanding occupations: a longitudinal perspective. J Organ Behav. 1994;15:101-27.

17. Hannigan B, Edwards B, Burnard P. Stress and stress management in clinical psychology: Findings from a systematic review. J Ment Health. 2004;13(3):235-45.

18. Ogińska-Bulik N. [Occupational stress in the profession of police officer. Sources - consequences - prevention]. Lódź: Wydawnictwo Wyższej Szkoły Humanistyczo-Ekonomicznej; 2003. Polish.

19. Johnson S, Cooper C, Cartwright S, Donald I, Taylor P, Millet $\mathrm{C}$. The experience of work related stress across occupations. J Manag Psychol. 2005;20(2):178-87, https://doi. org/10.1108/02683940510579803.

20. Sigler RT, Wilson ChN, Allen Z. Police stress and teacher stress at work and at home. J Crim Justice. 1991;19(4): 361-70, https://doi.org/10.1016/0047-2352(91)90033-R.

21. Ogińska-Bulik N. [Occupational stress and burnout syndrome in police officers]. Folia Psychol. 2003;7:27-35. p. 33. Polish.

22. Karasek RA, Theorell T. Healthy Work, Stress. Productivity and the Reconstruction of Working Life. New York: Basic Books; 1990.

23. Agarwal RN. Stress, job satisfaction and job commitment's relation with attrition with special reference to Indian IT sector. Manag Innov Compet Advant. 2015;9(1):720-31, http:// conferinta.management.ase.ro/archives/2015/pdf/76.pdf.
24. Griffin P, Klun CL. Laboratory stress: what causes it? Am J Med Technol. 1980;46(7):490-4.

25. Grant M, Bramm G, Zychla L. Describing Mental Health Issues for Medical Laboratory Professionals in the Workplace. Summary Report. Hamilton: Canadian Society for Medical Laboratory Society; 2016 [cited 2018 Mar 16]. Available from: https://www.csmls.org/csmls/media/documents/resources/Describing-Mental-Health-Issues-for-MLPs-v02.pdf.

26. Leiter PM, Maslach C. Areas of Worklife Survey Manual. Wolfville: Centre for Organizational Research and Development at Acadia University; 2006.

27. Maslach C, Leiter MP. Early predictors of job burnout and engagement. J Appl Physiol. 2008;93(3):498-512.

28. Cohen S, Kamarck T, Mermelstein RA. Global measure of perceived stress. J Health Soc Behav. 1983;24(4):385-96.

29. Juczyński Z, Ogińska-Bulik N. [Tools for measuring stress and coping with it]. Warszawa: Pracownia Testów Psychologicznych PTP; 2012. Polish.

30. Terelak JF, Izwantowska A. [Adaptation of the Areas of Worklife Survey C. Maslach and M. Leitera]. Stud Psychol. 2009:9:223-32. Polish.

31. Aranowska E, Rytel J. [Multivariate analysis of variance (MANOVA)]. Psychol Społ. 2010;5(2-3):117-41. Polish.

32. Violanti JM, Fekedulegn D, Hartley TA, Charles LE, Andrew ME, Ma CC, et al. Highly Rated and most Frequent Stressors among Police Officers: Gender Differences. Am J Crim Justice. 2016;41(4):645-62, https://link.springer.com/ article/10.1007\%2Fs12103-016-9342-x.

33. Matuszek PAC, Nelson DL, Quick JC. Gender differences in distress: are we asking all the right questions? J Soc Behav Personal. 1995;10(6):99-120.

34. Miller K, Greyling M, Cooper C, Lu L, Sparks K, Spector PE. Occupational stress and gender: A cross-cultural study. Stress Med. 2000;16(5):271-8, https://doi.org/10.1002/10991700(200010)16:5<271::AID-SMI862>3.0.CO;2-G.

35. Siuta J. [The NEO PI-R Personality Inventory by Paul T. Costa and Robert McCrae. Polish adaptation. A Manual]. Warszawa: Pracownia Testów Psychologicznych; 2006. Polish. 
36. Han M, Park S, Park JH, Hwang S, Kim I. Do police officers and firefighters have a higher risk of disease than other public officers? A 13- year nationwide cohort study in South Korea. BMJ Open. 2018;8(1), https://bmjopen.bmj.com/content/bmjopen/8/1/e019987.full.pdf.

37. Hellman ID, Morrison TL. Practice setting and type of caseload as factors in psychotherapist stress. Psychother. 1987;24:427-33.

38. Żak M. [Family life in the sphere of high-risk occupations (using the example of the police officer's profession)]. Katowice: Wydawnictwo Uniwersytetu Śląskiego; 2015. Polish.
39. Woszczyk S, Domaglska J, Żelazko A, Nowak P. [Stress and ways of coping with it in police officers and firefighters]. Bezpiecz Pracy. 2016;10:1-15. Polish.

40. Judzińska A. [Stress the Prose of Life - Analysis of Chosen Professional Groups in Perspective of Threatening Stressful Impulses]. Kult Społ Eduk. 2013;2(4):185-206. Polish.

41. Dyląg A, Łącała Z. [Innovativeness and Stress, Burnout and Work Engagement]. Studia Praw Ekon. 2014;92:243-61. Polish.

42. Ogińska-Bulik N, Kaflik-Pieróg M. [Work-related stress in rescue services]. Łódź: Wydawnictwo Akademii Humanistyczno-Ekonomicznej; 2009. Polish.

This work is available in Open Access model and licensed under a Creative Commons Attribution-NonCommercial 3.0 Poland License - http://creativecommons.org/ licenses/by-nc/3.0/pl/deed.en. 